\title{
MUJERES Y NEOCOLONIALIDAD EN LOS CONDOMINIOS DE LUJO DE CIUDAD DE GUATEMALA
}

Recibido: 04/07/2014 Aceptado: 29/11/2014

\begin{abstract}
Resumen
El artículo se refiere a los condominios suburbanos de clases medias y medias-altas que se extienden por el sureste de la ciudad de Guatemala y, desde las voces de sus mujeres residentes de estos, describe el estilo de vida de las familias en estos espacios. Expone también la reproducción de relaciones de neocolonialidad y de cultura de servidumbre que conlleva este mundo del privilegio. Finalmente propone en qué consiste la especificidad guatemalteca en esta tendencia global del habitar en fraccionamientos cerrados.

Palabras clave: mujeres; neocolonialidad; condominios de lujo; ciudad de Guatemala; privilegio.
\end{abstract}

\begin{abstract}
The article refers to middle and middle-high class suburban condominiums stretching to the southeast of Guatemala City and, from the voices of women living in the sames, describe the lifestyle of the families in these spaces. Also exposes the reproduction of neocoloniality relations and culture of servitude involved in this world of privilege. Finally proposes the Guatemalan specificity in this global trend of dwelling in gated communities.
\end{abstract}

Key words: women; neocoloniality; luxury condominiums; Guatemala City; privilege.

Este artículo se centra en las recientes colonias suburbanas y en sus residentes que forman parte de la expansión de las clases emergentes ganadoras de la globalización (Svampa, 2008). Abarca las características de la expansión de estos fraccionamientos en ciudad de Guatemala, lo que es el régimen de condominio y las condiciones que impone a sus residentes; el perfil de estos habitantes del privilegio y el estilo de vida que practican las familias que componen dichos espacios que emulan el espíritu neocolonial y que se acompañan de una cultura de servidumbre, lo cual se ilustra con los testimonios de algunas mujeres.

Finalmente, se proponen algunos puntos de la especificidad guatemalteca de esta tendencia global de habitar en condominio, en la privatización de la seguridad y el armamentismo; el ser servidos y la renovación de los arquetipos de género, el 
refuerzo cultural y político del evangelio de la prosperidad en los megatemplos, en la fuerza de la autorepresentación neocolonial simbolizado en la construcción del proyecto de Ciudad Cayalá, la reproducción de la secesión social hacia las nuevas generaciones con las implicaciones que ello tiene.

De este modo se plantea una serie de hipótesis a confirmar en investigaciones futuras: los condominios cerrados como símbolos de las actuales relaciones de poder y de las modulaciones culturales de las mismas; la concepción y las prácticas de relaciones sociales de corte neocolonial y neoestamental en el marco de la modernización globalizada y, junto a ello, el reforzamiento readecuado a este contexto de un orden de género patriarcal y altamente sexualizado y un retorno del criollismo y la supremacía de la blancura. Vendría a mostrar que estas formas socioculturales se darían con especial exacerbación en el caso de Guatemala.

Para desarrollar estos planteamientos cuento con una larga experiencia de vida e investigación en la ciudad de Guatemala, visitas específicas de observación a estos espacios, y una indagación de varios años en Guadalajara, México, donde los fraccionamientos cerrados tienen nombre propio, son "los cotos", lo que permitió elaborar un marco interpretativo para Guatemala (Camus, 2015). Parte importante de este texto son las entrevistas con conocedoras o residentes que se animaron a compartir sus vidas y experiencias. Se trata de 4 mujeres de edades entre 35 y 60 años, dos residentes en condominios de lujo (Pili y Jenny) y dos que viven en colonias cerradas de clase media y céntricas con mucho conocimiento e intercambio hacia estos sectores y espacios por sus actividades comerciales y sus extensos lazos familiares (Edda e Irene). Con todas ellas mantengo una relación de amistad y confianza por lo que sus comentarios se manifiestan frescos, ricos y críticos. ${ }^{1}$ Lo anterior es una evidencia empírica insuficiente, mas el impulso de presentarlo es invitar a seguir con esta indagación sobre las élites que históricamente tienden a fugarse del análisis social y estimular la producción de su conocimiento a nivel regional. Por otro lado, muchos guatemaltecos capitalinos, aunque no residan en fraccionamientos cerrados, se involucran y son cómplices de estos mundos con los que comparten parentesco, amistad, experiencias, algo cuyas implicaciones deberían ser cuestionadas. Los lugares comunes pueden ser "peligrosamente" comunes.

\section{La ciudad capital de Guatemala y el blindaje transclasista}

Las nuevas formas de habitar la ciudad desde fraccionamientos, colonias, condominios con muros y garitas de seguridad han colonizado extensos territorios en el área metropolitana de Guatemala (ver mapa 1). ${ }^{2}$ Esta ocupación del suelo urbano por supuestas comunidades de iguales bajo fuertes medidas de seguridad para resguardar el patrimonio y la familia no son nuevas ni en América Latina ni en el mundo, aunque resulten acordes a estos tiempos marcados por la polarización social. ${ }^{3} \mathrm{Su}$ boom actual está ligado a las violencias urbanas propias de la contemporaneidad y a las estrategias de las desarrolladoras inmobiliarias que lucran con esta coyuntura y modalidad al imponer este hábitat como el deseable (Cabrales, 2002). 
En ciudad de Guatemala fue la oligarquía la que inició esta secesión socialresidencial desde hace mucho tiempo atrás. A partir de 1944, las élites se desplazaron del Centro Histórico hacia la Avenida Reforma (zonas 9 y 10) y después hacia la Avenida Las Américas (zonas 13 y 14), Boulevard Vista Hermosa (zona 15) y Boulevard Los Próceres y salida hacia El Salvador (zona 14 y Santa Catarina y San José Pinula) (Gellert y Pinto Soria, 1990). Como antes con La Cañada ${ }^{4}$, desde finales de los ochenta, Santa Catarina Pinula y San José Pinula -y más recientemente la zona 16- se identifican como espacios de expansión de residenciales y centros comerciales, country clubs, golfs, entre otros. Ahora otros adinerados se escapan a estos paisajes límites en busca de disponer de terrenos "rurales", baratos y extensos.

El mapa 2 muestra la incorporación o refundación de la semirural zona 16 -que abarca de la colonia Vista Hermosa III a San Isidro- y la extensión de la zona 15 hacia el suroriente para la Carretera a El Salvador. En estos espacios pueden reproducir su deseada "distinción" de una forma despreocupada. ${ }^{5}$ Su estilo de vida que encaja con la promoción de una ideología conservadora en torno a "la familia" remarca el hecho de que se entiendan como en un "pueblito" donde comparten aspiraciones y esperan recrear infancias idílicas. En cualquier lugar semejante en América Latina se repite como salmo "cuando los niños podían jugar en la calle", "las casas no se cerraban con llaves" o "por darles esa oportunidad a los niños de que conozcan a su amiguito de a la par, que tú ya sabes que son gente confiable".

Hoy la afición condominial de vivir "asegurado" es transclasista y podría hacerse un modelo pastel según la ubicación de estos residenciales a lo largo de los ejes de comunicación de la ciudad de Guatemala; hacia el sur y a lo largo la carretera Interamericana se ubican los residenciales de clases medias y medias bajas; los más adinerados vierten hacia el suroriente o carretera a El Salvador; las clases medias bajas y bajas hacia la zona 18 y salida al Atlántico; mientras que adentro de la ciudad proliferan los barrios y calles cerradas y condominios que hacen el paso laberíntico y que reflejan dislocaciones extremas en todos los sentidos. Es común escuchar la palabra e imagen reiterada de "bunker" para referirse a los condominios cerrados y a la ciudad de Guatemala, en general, como "bunkerizada".

Las modalidades de encerramiento son muchas, pues hay residenciales verticales y horizontales, calles que se cerraron con el tiempo o que se diseñaron ya con muro y talanquera, los hay de estilo country y con estándares de adosados, se encuentran otros más caros, espaciosos y de élite, o más baratos, sencillos y abigarrados. Pueden darse diferentes criterios para categorizar los condominios, y complicarse al combinarlos, más cuando se añaden factores subjetivos como el estatus. ${ }^{6}$

Esta estructura corresponde al nuevo modelo urbano a nivel mundial, el cual es disperso y fragmentado y en el que las élites se trasladan a la periferia y establecen subcentros (Aguilar y Mateos, 2011). Se crean así las "islas de modernidad" compuestas por megaproyectos residenciales, comerciales y de oficinas. En estos desarrollos se genera una alta homogeneidad interna en cuanto a renta, junto a una reducción de la distancia física 
extramuros entre los grupos sociales de diferentes estratos socioeconómicos. Además, la segregación urbana se hace más intensa en la escala micro a través de bolsas urbanas aisladas entre sí, pero en un análisis desde la gran escala se "exhibe una aparente mayor heterogeneidad y los indicadores de segregación residencial se hacen menores" (Aguilar y Mateos, 2011: 10). Esta disposición de espacios, comodidades y servicios ofrece estatus para unos, pero profundiza las diferencias sociales afirmando la distancia social y la desigualdad. ${ }^{7}$

\section{Características de la vida condominial}

El régimen de vida condominial supone que hay propiedades compartidas por el común: calles, espacios verdes, instalaciones que requieren de acuerdos colectivos que relativizan la propiedad privada del lote y la vivienda. Además, la administración, las normas internas y las cuotas, al igual que en otros países, se rigen por acuerdo de sus habitantes en asamblea y por una Junta de vecinos, y no por instancias públicas como las municipalidades.

El atractivo que los condominios han tenido para desarrolladores, gobiernos locales y residentes se produce porque los primeros pueden regular el uso de los espacios comunes y reducir el riesgo de la degradación económica del condominio; mientras que los gobiernos locales se evitan problemas y se permiten delegar funciones, y los vecinos se benefician del nivel y calidad de los servicios públicos suministrados en lo privado gracias a sus cuotas de mantenimiento, mientras su autogobierno asegura el control del ambiente y permite gestionar una imagen de prestigio del vecindario (Glasze, 2005). Una de las mujeres entrevistadas se ríe de la palabra "mágica" que motiva al funcionamiento interno de los residentes: el que sus propiedades no pierdan valor, "todo el tiempo están diciendo 'hay que mantener estas calles, jla plusvalía que tiene!'” [negrita de la autora].

El éxito del modelo de condominio no se produce igual en todos los países, tiende a expandirse en Estados y democracias más débiles como Latinoamérica, donde se han mantenido las desigualdades étnico-raciales y de clase, así como la ciudadanía diferenciada, aquí es donde estos clubs territoriales-residenciales exclusivos adquieren más sentido y hegemonía (Glazse, 2005). ${ }^{8}$ Con todo, esta fórmula de convivencia en los condominios exige un aprendizaje de la gobernabilidad en colectivo porque, aunque los reglamentos sean aceptados, suelen darse conflictos por sus imposiciones cuando estas normas pasan por encima de los derechos individuales de los propietarios.

El vínculo del encierro con la seguridad es automática, a pesar de la pérdida de libertad que supone:

decidimos un condominio porque nos daba más seguridad, porque en la entrada tienes garita, ya no puede entrar cualquier persona a las casas, los carros están más controlados. En las calles se ponen cámaras de seguridad. Tú tienes unas cuotas que pagar, tienes reglamentos que cumplir, tienes que dar a la seguridad el número de placas, el número de visitantes, tienes que dar los DPI [números del Documento Personal de Identificación] de tu doméstica, del jardinero, de tus empleados. Te causa problema porque tienes que estar pasando un listado de todos los invitados 
si va a ser tu cumpleaños, sin embargo, lo valoras porque es por tu seguridad y no te pesa de estar dando ese tipo de información (Jenny).

Entrar y salir de estos lugares exige tener carro, con lo cual se cuestiona la pose antiurbana y la sensibilidad hacia la naturaleza de buena parte de los habitantes de las residenciales. El automóvil camioneta es todo un fetiche para estos sectores, pues la dependencia al mismo es total, en especial porque el transporte público no se concibe.

Ahora ya no es fácil caminar en la ciudad porque o te roban el celular, o te roban la bolsa o te quitan la cadena. Como me muevo más en la ciudad me da seguridad el carro, es una camioneta alta, está polarizada e intento mantener las ventanillas cerradas, entonces te da como una confianza. Todavía no he llegado a esa paranoia de blindarlo, pero si continuamos creciendo dentro del negocio, más adelante podría ser posible. Tengo un carro muy seguro, muy cómodo, a mis hijos les encanta, y ahora hay muchas comodidades en los carros, que televisión y todo, ¿me entendés? (Jenny).

Estos sectores que viven en comunidades aisladas y exclusivas se mueven entre islas o esferas, es decir, de espacios "liberados" a espacios "liberados": escuelas, clubs, hoteles, residencias y oficinas exclusivas, hiperprotegidos por guardias privados y acceso limitado donde dependen de ejércitos de sirvientes. Todo esto lo realizan dentro de una geografía urbana restringida:

ellas están seguras porque se mueven en un ámbito. Salen a Oakland y La Pradera, a la zona 10. Y a Miami ija, ja, ja! Guayito estaba contando el domingo 'nos vamos el 28 de noviembre a Miami'. Todos 'Miami, Miami', todo es Disney por los niños y hacer shopping. Miami es de caché o algo así, los centros comerciales son muy impresionantes (Edda). ${ }^{9}$

\section{Perfil de clase: distinción y consumo}

Edelberto Torres Rivas (2008) basándose en datos estadísticos presenta la estratificación social guatemalteca a través de un cochambroso inmueble de tres niveles hacia arriba y dos ocultos hacia abajo donde conviven más de once millones de guatemaltecos. ${ }^{10}$ Con ello destaca las distancias sociales, económicas y culturales de una sociedad desigual, más para la población indígena; así, la magnitud de la pobreza, representada por los habitantes de los dos sótanos y un buen sector del primer piso, y la distancia de la élite que vive en el penthouse. Es un edificio sin ascensores, es decir, una sociedad sin movilidad social ascendente.

Haciendo un resumen desde sus palabras e información para lo que incumbe aquí, en el segundo piso habita un "estrato medio", esa heterogeneidad de las clases medias del subdesarrollo que se mueven entre el temor de "caer" en la pobreza y las esperanzas de "subir" donde vive la gente decente. Son unas 900000 personas, de mayoría no indígena y urbanas. El 46 por ciento está constituido por empleados de la empresa privada y un 18 
por ciento por cuenta-propistas. Son familias de 2,1 hijos de promedio y su ingreso mensual y personal es de 1559 quetzales, ${ }_{11}^{11}$ lo cual les permite disfrutar de razonables condiciones de bienestar, un equipamiento doméstico a la altura de sus ideales de consumo pues pueden disponer de electrodomésticos, celulares, TV y DVD, computadoras, automóviles, etc.; además, el servicio doméstico aparece en un buen número de hogares. Los "estratos medios" poseen educación superior completa, empiezan a entrar a Internet, consumen vinos y licores extranjeros, hacen turismo interno y cuando pueden llevan a los hijos a Orlando. Los sectores bajos de este estrato medio exhiben un nivel de bienestar que en numerosos casos financian con tarjetas de crédito, por lo que se endeudan crónicamente.

El tercer nivel es el penthouse del edificio, el cual asemeja un apartheid social. Aquí habita el 1,5\% de la población nacional. Es una composición más homogénea y hay una minoría que concentra una altísima calidad de bienestar. Su ingreso mensual promedio es 384 veces más de lo que reciben quienes viven en el sótano del edificio social. Disponen de abundante servicio doméstico, choferes y guardaespaldas, e incluso tienen helicópteros, avionetas y lanchas de motor. Son los propietarios y gerentes de los más importantes activos tanto en el país como en el exterior, y sus principales fuentes de ingreso son los beneficios del capital invertido productivamente, intereses, bonos y otras derivaciones del capital financiero. Es una élite criolla o blanca europea; practican el racismo y las formas abiertas de discriminación en sus relaciones sociales. En su interior hay una importante interacción personal y grupal y un alto grado de organización gremial, al reconocerse como "los dueños del país" (ver Knazric 2007, quien confirma y refuerza esta radiografía a través de los testimonios estrictamente de oligarcas, y Martí i Puig y Sánchez-Ancoechea, 2013; Palencia, 2013; Bull, 2014; Valdés, 2015 para entender la persistencia de las élites centroamericanas y guatemaltecas en el poder). ${ }^{12}$

En este documento los casos a los que se hará referencia son parte del subestrato medio alto, algunos tratando de escarbar en los intersticios del penthouse. Aparecen gerentes de diferentes corporaciones: Kellogs, Johnson, Colgate, Cementos Progreso, dueño de empresas de seguridad privada o de fábricas de dulces, de escuelas privadas o restaurantes de moda y de puestos en el Mercado Central. ${ }^{13}$ También hay mujeres arquitectas, gerentes, decoradoras, vendedoras de ropa, de compra venta de inmuebles; y también se dan beneficiados de herencias de fortunas y rentistas, así como amas de casas y "ociosas". La diversidad del entramado social que se encuentra en los condominios de estratos medios altos y altos corresponde a "los que ganan con la globalización" (Svampa, 2008) y se podrían definir por la posesión patrimonial. Pues son más y mejores ciudadanos porque disponen de plata y son consumidores natos. ${ }^{14}$ Lo cierto es que no se encuentra una denominación apropiada: burguesía, oligarquía, élites, clases, emprendedores, sectores, privilegiados... que los englobe a todos.

$\mathrm{Al}$ igual que en otras ciudades latinoamericanas, hay un vínculo entre el boom de estos espacios amurallados y el blanqueo de dinero; estos son los preferidos de narcotraficantes de todas las jerarquías para vivir. 
En mi colonia son gerentes de empresas, ese tipo de tecnócratas, uno tenía un puesto muy alto en el INDE que gana 55 mil quetzales, esos funcionarios públicos o de la iniciativa privada que ganan mucha plata pues, yo creo que además está lleno de narcos (Pili).

Muchos residentes dicen que controlan su penetración, pero el dinero manda y se respeta entre sus propietarios.

Ellos compran. Suponete que vives en esta zona exclusiva y ya se entra un narco y la gente inmediatamente se da cuenta, ya mira guardaespaldas, ya les mira las cadenas y ya se preocupan y tratan de ver cómo lo sacan y son intocables los narcos ¿me entendés? Y aparte en esos condominios tú pedís 2000 dólares y el chavo te dice que quieren alquilar la casa por un año, digamos 100 mil dólares de una vez. Y por ganarse la comisión no les importa, ajá. Aquí ha habido narcos, los papás del Marioco. La otra cosa es que en una de esas se desaparecen los narcos y dejan todo lo que hay en la casa (Irene).

Se trata de una connivencia-convivencia cotidiana que se añade a la confusión de la demarcación de las categorías de clasificación social.

Las dinámicas sociales internas son complejas, moviéndose entre la fragmentación, la precariedad y la simulación. Aunque Torres Rivas ve dificultoso que se den procesos de ascenso social, los mismos se producen -como señala- de forma individual. Varios testimonios de emergentes arribistas señalan que: "Muchas de estas gentes vienen de sectores populares o escalaron porque se casaron con alguien con un poquito más de plata, porque vienen de familia pelada" (Pili).

Tengo una amiga que es de las nuevas ricas que vive en la carretera al Salvador, él es un ingeniero civil que empezó su fortuna hueveando en la municipalidad de Mixco y ha escalado. Yo le digo a mi mamá 'este sigue hueveándole a alguien, no sé a quién' (Edda).

La Cathy tiene pisto porque su papá fue ministro de Economía en el tiempo de Lucas, tengo la idea de que le aumentó al azúcar, y ahí como que le pasaron unas sus fichitas. Entonces él compró apartamentos, una casa y todo en la Avenida Las Américas y heredaron a los hijos (Edda).

El arribismo, como mostraba Torres Rivas respecto a los habitantes del $2^{\circ}$ piso, se vincula con los comportamientos de distinción extrema cayendo en el dispendio. ${ }^{15}$

Es impresionante, he ido a bodas que cuestan 300000 quetzales y solo en flores se gastan 30000 quetzales. Fui a la casa Santo Domingo y eso comenzó a las 8 de la noche y a las 4 de la mañana yo decía 'no puede ser, no lo puedo creer', se habian gastado 30000 quetzales en flores y metiendo en la basura todo. Ella se casó con un millonario, el patojo tiene 24 años, trabaja en el banco Uno. La suegra es dueña de un colegio muy famoso y el papá de una empresa, tienen apartamentos en Miami. Suponete que la fiesta costaba 300 000, pagaron 150 000. Los papás de la novia son industriales, no son multimillonarios pero se tenían que poner al nivel. Pero 
tienes idea ;30 000 quetzales en flores!, qué no haría uno con 30000 quetzales ¿no?, pero ellos lo tiran en flores, y en velas porque tenian el salón con más de 1000 velas (Irene).

Sin embargo, suele ocurrir que buena parte de la administración de los gastos funciona entre los delicados manejos de los créditos y el dinero electrónico:

Yo me he dado cuenta de que la gente tiene dinero pero a raíz de préstamos y viven ahorcados" (Edda), o "Vendo joyería y bisutería y la gente de clase media te paga mejor que la gente de dinero, son más formales te dan 200 mensuales pero te los dan. La María Luisa que vive en La Cañada, el mes pasado me da un cheque de 150, me sale sin fondos y le cobran 125, pero vas a la casa de ella y hay de todo, vive sobregirada de todo lo que se mete (Irene).

Por ello es importante señalar que muchos son ganadores precarios. De repente sus puestos pueden desaparecer y verse sumidos en la crisis de estatus y posición social, entrando en dramáticos procesos de desclasamiento y viéndose expulsados de estos paraísos.

Olga tiene un matrimonio de 25 años, arquitectos que han vivido una apariencia de pagar 5000 quetzales de alquiler pero viven en la zona 15, los hijos en la Landívar. Y ahorita con la problemática de la construcción tienen 2 años de una crisis que no se levantan y la güira tuvo que dejar de estudiar y ponerse a trabajar en el banco GET y tratando de ver si consigue media beca (Irene).

Mi primo fue el primer ortodoncista de ese centro comercial, hizo dinero, bum, bum, bum... el terreno en Las Lisas, lancha, cuatro carros deportivos y todo. Hace unos 5 años comenzó a bajar, de ser un ortodoncista, fueron 5, después 10 y ahorita hay 20 en el mismo centro comercial y su hijo en la Marroquín y el otro en la Landívar, mercadólogo. La clínica ya no le da y empezó a vender sus cosas, un terreno en San Cristóbal, el otro terreno y ahorita acaba de vender una casa en San Lucas (Edda).

Pili se refiere a una conversación que sostuvo con un muchacho que hizo un estudio de capacidad de pago y sectores de población de esta zona, él decía:

¿Por qué creés vos que todos los comercios que están en la carretera El Salvador quiebran?, ¿por qué al Condado Concepción le dicen Condado Decepción? Porque no venden, todo es el estatus, te venden carísimo y la gente no puede pagar lo que venden ahí porque están pagando sus casas. En la zona 7, ¿por qué creés vos que todos estos comerciales están en la Roosevelt, el Miraflores, son exitosísimos? Porque esas gentes llevan 40 años viviendo ahi y ya pagaron su casa y es una clase media-media que tiene más capacidad de pago que la que puede tener la gente que viene a carretera El Salvador. ${ }^{16}$

Como dice Pili sobre sus vecinos en un residencial de la Carretera de El Salvador, por aparentar es que "comen mierda y eructan pollo". La tan deseada distinción produce niveles de simulación abundantes por las anécdotas que se escuchan. Refiriéndose a la zona 
16, incluye condominios más modestos lo importante es que "te das el lujo de decir 'yo vivo en la zona 16"' (Edda). Otros casos de pretensiones significativos es la familia que decide hacer la piñata al Km 18 y medio de la carretera a El Salvador y "el patojo vive en el cementerio de Las Flores" [municipio de Mixco en las antípodas de esta zona] o "he oído gente que hace supermercado allá arriba con tal de estar ahí es como un estatus de esa parte" (Edda).

Los hijos de esta "burguesía" heterogénea acuden a colegios privados y a universidades como la Francisco Marroquín, la del Valle o la Rafael Landívar donde se reproducen las relaciones necesarias para el futuro. Por ejemplo Del Roble, Campoalegre, Decroly Americano o el Interamericano que

es uno de los colegios más altos de Guatemala, ahí es prohibitivo, su hija se relaciona [con compañeros] que los papás tienen helicóptero, casa en Miami, todo así, se maneja con ese medio, la burguesía de ese tipo de colegios. Dice que la mayoría de mujeres no trabaja, las mamás solo se dedican a hacerse la cirugía plástica, se mantienen en el gimnasio, en los tés, todo eso... Y los pobres papás que no tienen se endeudan para hacer fiestas. Una cosa es pagarles el colegio Interamericano y otra cosa todo el paquete que viene alrededor de eso, tienen que tener la clase de piano, de pintura, talleres y la ropa, porque todas son modelos, y las piñatas porque ahora el cumpleaños se celebra en centros comerciales y entonces te ponen uñas a las niñas (Irene).

Finalmente, la rigidez de las oligarquías dificulta y tensa estas pugnas sociales porque

la burguesía no te deja entrar, la burguesía te podés poner de chongo, de esto, del otro y no" (Irene) o "vos sabes cómo son aquí los ricos... la mona aunque de seda se vista, mona se queda, el que es pelado y todos saben que es un pelado jamás va a ser amigo de ellos (Pili).

\section{Neocolonialidad y la generización del espacio}

En estos fraccionamientos cerrados sus actores principales comparten unas aspiraciones y "cosmovisiones" que se entienden como neocoloniales y neoestamentales. En el contexto actual de polarización y desigualdad social, persiste la huella colonial sobre las relaciones étnico-raciales, de clase, género, cultura, ruralidad, e incluso por la procedencia de las migraciones. Los sectores sociales involucrados viven en un mundo "moderno" que permite que ciertos grupos manejen en determinados momentos y espacios formas de respeto, derechos y distinciones por su estatus, poder y recursos patrimoniales. Aquí se utiliza el término neocolonial para remarcar la renovación o actualización de estas prácticas que se ven impulsadas y legitimadas en las condiciones de neoliberalismo global pero, para no hacerlo intrincado, se asocian y se utilizan de forma indistinta los términos colonialismo y estamentalismo aun cuando suponen relaciones sociales de distinta naturaleza que pueden encontrarse combinadas como es el caso. La experiencia colonial se produce en territorios y dominios extensos donde el etiquetaje racial 
suele marcar y justificar las diferencias y la dominación. ${ }^{17}$ Así, los estamentos remiten a relaciones más personalizadas entre patrones y siervos o servidumbre, que puede darse en todo tipo de sociedades sin que medie la marca racial. Las relaciones estamentales actualizan la propuesta de Weber (1967) como posiciones sociales que grupos sociales y étnicos creerían basadas en privilegios adquiridos porque sí, aunque actualmente no reclamen el darse por nacimiento, ni por herencia. Más bien, sería la pretensión de sectores sociales que querrían mantener prebendas y oportunidades basadas en las normas y valores que impone el mercado y en su capacidad de acceso al consumo.

Reforzando lo anterior, en estos residenciales la diferencia de hombres y mujeres se naturaliza de forma jerárquica y especializada. El género es una estructura paralela de poder y explotación, que funciona de forma análoga al capitalismo (Connell, 2014), y que, en países como los latinoamericanos, obliga a referirse a la historia colonial. El imperialismo colonial incorporaba en su estrategia de dominación el orden de género que quebró las estructuras previas de sexualidad, familia y herencia. Fue una ocupación masculinizada (Connell, 2014), y de su mano se impuso con violencia constitutiva la colonialidad del género (Lugones, 2008). Esta idea y práctica perdura y permite entender que las mujeres son parte de las economías sexuales donde juega con fuerza la históricamente ocultada relación de género con raza. Las mujeres víctimas de la colonialidad del poder-género son las no blancas que sufrirán ambos procesos de subordinación. En términos muy simples, la división del trabajo del capitalismo patriarcal se basa en la apropiación del valor del trabajo de la mujer que se hace cargo de la reproducción de la fuerza del trabajo en lo doméstico y en lo estructural, donde se distinguen complicidades y subordinaciones al dividendo patriarcal según la posición social y la raza de estas mujeres (Connell, 2014). Es decir, las mujeres de la élite o de sectores emergentes de clase media alta y alta se entienden como mujeres blancas o blanqueadas. Ellas no son inmunes a las jerarquías patriarcales a las que pueden incluso enfrentarse, pero suelen ser parte cómplice de este sistema porque se benefician de la colonialidad del poder al ser favorecidas por la clase social, y de la colonialidad de género-racial que permite la "natural" subordinación del servicio - por ejemplo doméstico y de cuido- a su favor.

\section{Las mujeres, "siempre ladies"}

Como también ocurre en Guadalajara, México, el esfuerzo de la representación de familia perfecta protagonizada por muchas mujeres de estos fraccionamientos se hace extensivo a otros campos de la apariencia y el "como si". La frescura que puedan aparentar supone una intensa actividad, deben ocuparse de los hijos y de la educación de estos, verse presentables hacia el mundo público y estar al día en la moda, cumplir con eficacia su gasto y que se note el consumo, manejar la vida social hacia la familia extensa y las amistades, las relaciones en el club, la gestión de los viajes y del ocio, el empleo o actividad remunerada si la hay, la nutrición del conjunto, la dirección de la servidumbre, las mascotas y la jardinería, los servicios socioreligiosos. 
En Guatemala, el ama de casa o madre-esposa sigue siendo el modelo hegemónico del sistema sexo-género y el mercado matrimonial marca la pauta a las mujeres: "Las hijas de la Mari Chuy ellas se casaron súper bien y todas viven allá [en carretera a El Salvador y zona 16]" o "Todas se casaron de pisto", aunque se abre paso a ciertas modalidades relacionadas con contextos y procesos de cambio. ${ }^{18}$ Como en otras ciudades y países el proyecto absorbente de maternidad y de familia se ha modificado drásticamente: las mujeres cierran más pronto su ciclo reproductivo. La planificación familiar facilita controlar a la baja el número de hijos y terminar antes con el periodo de crianza: su cuerpo no solo va a ser reproductor, por lo que pueden disponer de más tiempo para sí mismas.

Lo anterior se puede ejemplificar con el caso de la señora Arzú Castillo, mujer de la élite guatemalteca, quien se representa en su autobiografía como precursora de una nueva feminidad y expresa la visión del mundo y de la sociedad de los sectores oligárquicos (2005). Ella se casa en tres ocasiones y se hace cargo de seis hijos entre propios y ajenos; vive entre España y Guatemala disfrutando del cosmopolitismo que le permite una posición económica holgada -es parte de la Cervecería Centroamericana de la familia Castillo-. Participa en la Cruz Roja, incursiona en el periodismo y en el mundo del turismo desde la Embajada de Guatemala en España o como subdirectora de Turismo en el Gobierno de Méndez Montenegro. Hasta sabe pilotar avionetas. Pero, como se trata de mostrar, Odette -aun siendo una mujer "transgresora"- se beneficia de los dividendos de su posición de clase permitiéndose comentarios críticos sobre la desigualdad y el racismo: “Es una tristeza que en este bello país los salarios fuesen tan bajos” (2005: 79) o "El dinero está muy mal repartido y hay que reconocer que el pueblo era y es santo, sufre en silencio, esperando que se abra el mundo para ellos" (ibid.: 29). Pero en ningún momento expone responsabilidades ni cuestionamientos a los miembros de su entorno. El objetivo de sus memorias se dirige a la autocomplacencia hacia sí y su círculo/casta. Sus obsesiones se centran en el shopping, el disfrute, la belleza, las fiestas, los hombres, la familia ejemplar... Por su parte, la situación familiar que describe no responde a los patrones de la sumisión femenina en Guatemala, pero sus aspiraciones no quiebran el orden patriarcal-oligárquico del grupo al que pertenece, más bien es arropada por ellos, las suyas son equivocaciones plausibles y aceptadas. Odette afirma esta aceptación del madresposismo cool de la élite donde todos son preciosos, simpatiquísimos, matrimonios ejemplares o, si no, "lástima que su matrimonio no funcionó" (2005: 8).

De hecho, estas mujeres manejan su tiempo libre con una socialidad más intensa entre ellas, participan en cuchubales -loterías de petit comité-, van al gimnasio, y es típico que después de las tareas de la mañana -más para las que cuentan con menoresse junten a desayunar en lugares como: La Decorísima, El Portal del Ángel, Casa Escobar, Sarita, La Estancia, Los Cebollines, el Hotel Camino Real, "nice todo. Vas a un restaurant y está lleno de mujeres, la mayoría no trabaja" (Irene). Las mujeres pueden trabajar, estudiar, socializar, hacer deporte y disponerse a desear y a disfrutar, es decir, que aunque pueda tratarse de un estilo de vida y de ser mujer compartido más ampliamente se complementa, potencia y facilita con el hecho de vivir en el condominio. 
La vida en el apartheid residencial supone la transformación de la mujer "ama de casa" -que se encargaba de manera más personal del "cuidado" del hogar y la familia a la mujer "gestora del hogar", una administradora doméstica que requiere una planificación estricta de la cotidianidad desde un espacio domiciliar aislado (Camus, 2015). Algo que no es nuevo pero que introduce un acento diferente. Todos los movimientos de salida, desde escuelas y actividades extraescolares de los hijos, trámites administrativos, salidas de ocio y shopping, de compras de alimentación y abarrotes, y de visitas diversas suponen la necesidad de agendar las acciones del diario.

Las mujeres, incluso las profesionales, han dedicado el tiempo de crianza a los hijos. Ya después de que ellos se autonomizan, muchas terminan estudios y se debaten en el sumarse al mundo laboral, la vida "ociosa” y otras tantas dedicaciones centrífugas al hogar que suponen opciones al proyecto madresposiano. Pueden generar recursos económicos propios como un hobbie, por ejemplo:

Cathy de La Cañada es gente de dinero de muchos años. Hizo su curso de arreglo de flores en lo más alto de esos lugares, en el club Jardín. Solo las mujeres de pisto pueden entrar a eso, porque recibir el curso te cuesta 2000 quetzales. Ella ya se dedica a eso, es profesional, pero muchas solo por el hobbie (Edda).

Así como Cathy, muchas otras mujeres cuenta con sus ingresos propios: “Unas viven para comprar, su sueldo es para echárselo encima, se compran lo que quieren. Y les gusta trabajar y tener su dinero". De esta manera no dependen de sus esposos y son "compradoras compulsivas". Otras mujeres buscan otro tipo de empleos pero lo común que sus oficinas o espacios de trabajo estén en sus viviendas u alrededores. Una situación típica podría ser la que expone a continuación:

En un fraccionamiento en San José hay un pequeño centro comercial. Una chica que vive ahí adentro alquiló un local y vende pisos de madera. Ella no trabaja solo para la gente del residencial, tiene un mercado más grande pero tiene su oficina ahi, porque hace eso pensando en sus hijos. Le resulta fácil recoger a los niños, que el bus llega y le resulta fácil ir a ver lo de la comida. La mayoría de las mujeres de alli están en el rollo de cuidar a los niños. Creo que las pobres no lo hacen porque el periodo de la maternidad es muy fuerte, es la culpa con la que muchas mujeres se van a trabajar y dejan a los hijos. Estas tienen como pagarlo y tienen la posibilidad de poner ahi su oficinita, las otras hacen brincos y pericos para poder estar asi en su rol de la maternidad (Pili).

Muchas están atenidas a las decisiones del marido como detalla Irene: “a la esposa de mi primo yo nunca la he visto usar una chequera, es lo que él le compra, él es el que maneja el dinero", o a fungir como "llaveritos" que deben responder a la imagen del esposo, 
hay unos hombres que les gusta que sus mujeres anden como muñecas. Igual la Luisa, nos dijo que a él le molestaba que su mujer salga sin arreglarse, que eso no le parece. Esta patoja en Europa no pudo andar con tenis, tenía que andar con trancas porque eso le da elegancia. Ella es de gimnasio todos los días, no puede tener un centimetro de gordito. Ella se puso busto, se hizo una operación aqui que se vio malísima y dice "no me vuelvo yo a operar" (Edda).

Una observación describe cómo muchos hombres tienen como

característica horrible que las manosean enfrente de la gente. O sea, está una allí y él le está agarrando las nalgas así como "Estás buenísima!". Mi primo es asqueroso y mi cuñado fue exactamente igual, ellos te están diciendo "ah verdad que estuvo buena la noche". Mirá, solo ven entrar a una mujer patoja y la desnudan. Tienen 40 años. Yo los veo así como de esa clase media alta que se formaron en esos colegios desagües, de medio niños ricos, medio no, en la zona 10, niños abandonados, acostumbrados a la zona viva, a la prostitución... esa es la onda. Es un sector como de finales de los ochenta, que crecieron en ese medio. Luego tienen mucho pisto y son evangélicos todos jimagínate!, evangélicos y los ves cómo se visten y si se ponen a bailar las hijas, te quedas asustada, porque son evangélicos entre paréntesis (Edda).

Las operaciones del cuerpo -y los gimnasios- están a la orden del día en un mundo en que el culto al cuerpo es radical:

La Mechitas se quitó un pellejito, y jes una mujer que tiene un cuerpazo! Y le fue peor porque la cicatriz le quedó peor. Y tiene que usar el pantalón. Me ha extrañado porque las últimas veces no la he visto pintada o no sé si ya se cansó (Edda).

El chiste está servido "Como dijo mi hermano 'si uno se acuesta con una mujer y las registra, todas son costuras'". Y las operaciones son un motivo de presumir ante los conocidos y motivo de pláticas y competencias:

La Mechitas se ha hecho la nariz, se ha hecho el busto, se ha hecho la panza, la Cuca igual, la Maggie igual. La Paty se hizo el busto como a los 22 años y el regalo de las niñas de 15 años y de 20 años es que te pongan busto. $Y$ enseñan todo y son provocativas y vas a esas piñatas de la carretera y todas las patojas son pero que las miren, "imirenme!".

Así, cualquier encuentro social como un cumpleaños es un desfile de modas y cuerpos donde todas han de ir entalladas y con grandes escotes ("parecen peperecho", sentencia una informante). Al respecto, David Le Breton (2002) afirma que hoy el cuerpo es entendido como imperfecto, una anomalía, un "borrador por corregir", una máquina que es mejorable con la cirugía estética, regímenes alimenticios, cosméticos o tatuajes, y culturismo. Se vive un cuerpo rectificado para alcanzar una supuesta dignidad que no tenía el cuerpo propio. Este afán narcisista-hedonista, en el sentido 
no tanto de búsqueda del placer, sino de separar a la persona y el cuerpo, diviniza al segundo con su presentación o look en aras de la apreciación de la identidad propia. ${ }^{19}$

Otro indicador de cambio en las concepciones de la vida cotidiana familiar es la creciente individualización. ${ }^{20}$ Una de las manifestaciones se produce en las relaciones entre progenitores e hijos casados. Irene comenta

siento que la mayoría de los jóvenes ahora les ponen una barrera a los suegros, aquí tienen que decirle ahora a las patojas "voy a ir", si no que "¿van a estar, puedo ir?". Como que la familia extensa antes tan fuerte ya se es más de la familia nuclear. Ya no es como aquella cosa de antes de que los domingos te juntabas a almorzar, ahora ya no. La esposa de Fredy le pone un limite a la Mariela y a Ponchito. Decía "es que casi que le tengo que avisar 15 días antes si voy a llegar" y le pone una barrera.

Una amiga contaba a Edda, mi entrevistada:

ya casi no puedo ver a los nietos porque esta cabrona saber que se cree porque "¿cómo está la nena?", "está durmiendo", nada de que "pasa, no tenga pena, cárguela". Ahora hasta te dicen "¿y se lavó las manos para cargarla?". Es como decir "este es mi espacio y este es su espacio y aquí cuando queramos.

En otro momento le dice:

Antes cuando se preparaba una boda cómo se hacía partícipe a las mamás, ahora siento yo que el novio y la pareja deciden todo, no toman mucho en cuenta a los papás y te cortan porque antes invitabas al chucho, al gato, a todos de la familia, ahora los patojos ya se imponen cuando se van a casar.

Habría que analizar si esta individualización entre familias y sujetos donde están jugando el espacio y la desconfianza no se vincula también con el extrañamiento a los orígenes plebeyos de esta sociedad emergente.

Todo este conjunto de prácticas remiten a estrictas responsabilidades para la mujer de estatus que son parte de la violencia simbólica [y autoinflingida] a la que se ve sometida (Bourdieu y Wacquant, 1992), un exceso de responsabilidades y proyectos, pues deben cumplir la norma histórica de la madre-esposa -aunque sea desde la lógica marcada de la gestión/planificación/agenda-combinándola con la perfección corporal y la perfección sociocultural. Por esto, si se hace la pregunta ¿qué tienen estas mujeres que no tengan otras en un contexto de creciente democratización y transclasismo del gusto, el consumo y las marcas? Mi explicación es que ellas cuentan con una posición sociocultural y económica específica. No solo más disposición y acceso al consumo, sino que constituyen un sector social con el poder de generar aspiraciones e imaginarios sobre otros sectores, son como una "clase vitrina". Ellas representan el estatus del esposo y de la familia patriarcal como conjunto, son el estandarte del honor familiar y por ello sufren un control-presión social que las genera una mayor responsabilidad (Veblen, 2005). ${ }^{21}$ 
Desde una perspectiva global, cuando Eva Illouz (2009) conecta el amor y las emociones románticas con la cultura del capitalismo tardío y sus relaciones de clase, señala que el orden social ha cambiado y ahora se reconoce la libertad, el autoconocimiento y la autorealización e igualdad como se esperaba del amor romántico. Esto nos da luces sobre el comportamiento de estas mujeres y de su contexto y la representación de "familia feliz estilo McDonald's o al gusto del mercado".

Así, el "tecnocapitalismo" ha convertido el campo del amor romántico en un espacio cultural en sí mismo; en un bien de consumo. Son estilos de vida donde se disfruta de la trascendencia de la belleza, la juventud, el glamour, la fama (Illouz, 2009), y el tiempo libre se ocupa en cines, restaurantes, bailes, viajes, que son parte del mercado y la mercadotecnia; es una supuesta transgresión con que se vende el consumo del ocio y de la naturaleza y que se liga con la dinámica de la distinción. Esto resulta significativo para el argumento de este texto, el cual propone que son las clases altas las que tienen más oportunidad y posibilidades de alcanzar estas metas de amor romántico (Illouz, 2009).

\section{La cultura de servidumbre}

El ideal neocolonial en estos residenciales precisa del mantenimiento de estas grandes residencias que suponen una creciente "tecnologización" y la "mercantilización del hogar" y de la vida íntima con la necesidad de "comprar" los servicios de cuidado personal y familiar que antes desarrollaban de forma más personalizada las mujeres de los hogares (Russell, 2008). ${ }^{22}$ Para lograr la vida a que aspiran, estas mujeres y sus familias deben "pagar" y "dirigir" los servicios de cuidado personal y familiar y las tareas tradicionales en el hogar con domésticas, guardias de seguridad, jardineros, mozos, hasta terapeutas y profesores privados... El servicio doméstico ha sido una constante para estos sectores de clase media alta y alta, pero aquí se vuelve más obvio.

De manera que en los condominios se encuentra una extrema simplificación social que se representa en dos tipos de mujeres: las patronas y las sirvientas, cuya relación, en principio, se produce a través de la "cultura de servidumbre". El estatus de neocolonialidad en el que quieren moverse todos estos sectores de los fraccionamientos de la zona 16 y la carretera a El Salvador pasa en muy buena parte por el mandar y el "ser servidos", es decir, por cultivar una cultura de servidumbre y un entramado de relaciones de poder y jerarquías que requieren para el nivel social y la vivienda que pretenden. Es una cultura "donde las relaciones de dominación/subordinación, dependencia y desigualdad, son normalizadas y permeadas por la esfera doméstica y la pública" (Ray y Qayum, 2009: 3). Se trata de un sistema vivo de significados y valores -constitutivo y constituyente-, el cual se experimenta y se conforma recíprocamente, de tal manera que la dominación, dependencia y desigualdad no solo es tolerada, sino también aceptada por las partes de este orden hegemónico que se reproduce en la interacción cotidiana. En Guatemala esto supone refortalecer las bases históricas del racismo y la inferiorización de los subordinados. $^{23}$ A pesar de los diferentes orígenes sociales, los habitantes de condominios comparten un ideal neocolonial y neoestamental sobre el servicio doméstico que se manifiesta a 
través de la cultura del disponer de personas para lo que se les ofrezca. La persistencia del colonialismo interno en la historia de Latinoamérica ha consentido el uso de mano de obra indígena, rural o campesina como un hecho natural. ${ }^{24}$

Ilustrar estas relaciones no es difícil, abundan las anécdotas. En una conversación de Krznaric con Olga Alvarado de González, una mujer que trabaja sobre la oligarquía:

Ella me dijo cómo una cultura de muchachas, choferes y otros sirvientes hizo posible su estilo de vida adicto al trabajo: tengo la suerte como para tener a alguien que me ayuda a hacer las tareas domésticas. Ella es muy trabajadora y va al supermercado y cosas por el estilo. Tengo un conductor que lleva a mis hijos a la escuela y conduce a la criada al mercado. Y tengo un tutor privado para mis hijos, que viene todas las tardes para ayudarles con sus tareas escolares. Si no fuera por todo esto, yo no podría estar aqui (2007: 34-35).

O, como se expresa Arzú: "no soy muy amante de arreglar el hogar ni cocinar; siempre he tenido un servicio estupendo que todo me lo ha hecho" (2005: 76), mientras se refiere a "mi chofer" o a "nuestro querido mayordomo".

Sin embargo, muchas mujeres no oligarcas no valoran estas dependencias y apoyos de la servidumbre. Pili se refiere a una vecina como "negrera", pues no deja salir a la trabajadora doméstica de su casa más que cada 15 días. Un día invitó a esta vecina a un café y le planteó el abuso:

"no es posible lo que hacés, ni sábado ni domingo se trabaja" -le dije, 'y si trabajan sábados es hasta el mediodía, cómo es posible que cada quince días la dejés salir, es que eso ya no se usa Livi", "pero ¿y qué hago yo entonces?". "Pero si vos no trabajás, ni siquiera trabajás adentro de tú casa, ni siquiera sos de las que llevan la ropa a la lavadora". Al final me di cuenta que no entendía. No me habló más.

Al retomar lo planteado sobre colonialidad y raza, se observa que los comentarios y justificaciones racistas están "a la orden del día", como "a las indias uno las necesita, pero uno tiene la culpa por enseñarles a leer' me dijo. Básicamente vino a decir lo mejor es que se mantengan estúpidas" (Pili). Estos sectores se ponen nerviosos con esa presencia cercana de "los pelados y oscuros", con humor Pili narra:

Otra vez en la junta directiva dijo uno "hay una queja de vecinos que los albañiles juegan fútbol en la calle y que estorban el tráfico". Y les dije "bueno, que se vayan al área verde a jugar, si para eso es", "estás loca" me dijeron "y que los niños estén escuchando vulgaridades". Yo me le quedé viendo y le dije "jah! es que la gente como vos no dice malas palabras porque mirá que yo las digo permanentemente y las digo aquí o en el área verde o donde putas sea".

En otras anécdotas, surge la identificación de estos sectores subalternos -de los que dependen- como seres amenazantes y sospechosos: 
Es lo primerito que piensan, la premisa de que como son pobres y son ladrones, porque esa relación la hacen, esa condición para ellos es inevitable iverdad? y "aquí adentro hay albañiles"... Todos los trabajadores de casa particular, los albañiles, los vendedores, todos ellos son potenciales enemigos de toda la gente que hay (Pili). ${ }^{25}$

Lo anterior se relaciona con la idea de contaminación. Para la antropóloga Mary Douglas (1973), una comunidad no sobrevive sin un compromiso de protección entre sus miembros, y en sociedades de castas y estamentales, especialmente delimitadas y rígidas, se desarrollan complejos sistemas de pureza e impureza que penalizan las múltiples transgresiones a las que pueden verse expuestas. En este sentido se dan innovaciones como la siguiente que tienden al extrañamiento de la servidumbre y a la asepsia:

todavia hay que los niños los cuiden las empleadas, pero en ese nivel medio alto es Day Care, es para cuidar los niños. Y ahora las que pueden prefieren tener a los niños en un Day Care y no que lo cuide la empleada. Esta súper de moda aquí. Llevan los niños desde los 3 meses a estimulación temprana. Es el boom ahorita entre las patojas de pisto. Tres, cuatro, seis meses y que gatean y que quién gatea más y que les enseñan otra babosada... Es más profesional porque hay enfermera, hay nutricionista, los buenos tienen hasta doctora, tienen la directora, las niñeras. Es un dineral, pero prefieren no tener una empleada (Irene).

Además, la normalidad es depender del servicio y poner en práctica estrategias punitivas: "una vez tu doméstica renuncia, no puede trabajar con otra familia ahí" (Jenny). Y Pili, de la carretera a El Salvador, expone que en la Junta Directiva quisieron crear una "lista negra" de trabajadoras domésticas:

entonces el licenciado "yo quiero proponer que hagamos una lista donde todas las señoras que han tenido trabajadoras ladronas que pongan el nombre, para que nadie la vuelva a contratar". Yo me paré "mire a mí me gustaría que pusiéramos una lista de todos los hombres que golpean a las mujeres para que ninguna salgamos con ellos, esa es la lista que yo quisiera hacer". Todos se me quedaron viendo y "por favor ella lo que está ofreciendo es un servicio a la comunidad", y les dije "¿y lo mío no es un servicio?, claro que es un servicio para todas las mujeres, porque imagínese que uno de esos me enamore a mí y yo me enamore de él y es violentador".

Irene conoce bien estos ambientes sin pertenecer a ellos y se duele de lo que ve en estos círculos y, sin tapujos, expone:

Esas personas tienen ese poder económico porque utilizan al ser humano. [Para ellos] todos los empleados son huevones, haraganes, ladrones, no merecen nada, pero por ellos es que hacen el dinero, por eso tienen sus viajes, por eso la mujer tiene una camioneta Volvo. Hablan de la gente que les hace el dinero de una forma tan despectiva que te mata, jay es que es horrible! Paty es la explotadora más grande, enferma, es creída, jay es prepotente!, jay es fea! Cada que llego a su 
casa hay una empleada diferente. No la aguantan, todo lo tiene bajo llave. Y hay gente de clase media alta, como Lucy, ella le sirve al empleado para medirle la comida, para que no se pase con los frijoles '¡como hartan, todo se lo acaban!' ¡Así se expresan!". Irene nos descubre el centro de esta lógica: "Le digo a Chito 'mirá ipor qué tenés vos pisto? Vos no tenés pisto porque vos estás haciéndolo sino porque tienes una máquina de gente que te lo está haciendo".

Frente a esta explotación se observa un sofisticado manejo de las presencias, y es interesante cómo tratan de que la servidumbre no aparezca. Razón por la cual se apropian del trabajo y esfuerzo de los subordinados con lo cual aumenta su desvaloración: "Pati te recibe ella y te atiende y pareciera que es ella misma [la que lo limpia] ¡Ah! y te dicen de que les pagan muy bien, les pagan 1500, y que les pagan súper bien". Como señala Honneth, el "mirar a través de alguien" o mostrarse intencionalmente indiferentes a las personas presentes, expresa desprecio, falta de reconocimiento y demuestra insignificancia social (2004). La invisibilidad de la servidumbre es otro indicio simbólico de este estilo de vida; por ejemplo, en la publicidad que venden estos paraísos muestran niños y papás sonrientes y blancos en un ambiente verde y puro, sin que aparezcan los rostros oscuros de la servidumbre.

Por último, una historia ilustrativa de la concepción social estamental y jerárquica que practican es esta donde las relaciones que se establecen en otros países les confrontan el privilegio en que se asumen:

él no fue de pisto, pero ya es de dinero y lo oyes hablar jcon una prepotencia! Europa no le gustó, Italia es lo peor que le pudo haber pasado. Dice que fue asqueroso, que todos los choleros te tratan como que si fueras igual. Y él ama Estados Unidos. Pero lo que te quiero decir es que es una característica de todos esos jóvenes (Irene).

\section{El exceso neocolonial}

Condominios, individualismo, arribismo, megatemplos, colegios bilingües, mercantilización de la vida íntima, ser servidos, racismo y desprecio por el resto social, cuidado de los cuerpos, consumo exacerbado... en el teatro del exceso todo va de la mano.

Las siguientes son posibles explicaciones de la especificidad social de la Ciudad de Guatemala a través de estas historias que se refieren a mujeres residentes adineradas de los fraccionamientos cerrados de la Zona 16 y la carretera a El Salvador. Entiendo que estos residenciales son parte de procesos mundiales y que reflejan las transformaciones del llamado capitalismo corporativo o de acumulación por desposesión o del mundo poscolonial en tiempos de neoliberalismo o del capitalismo gore, según diferentes autores. La reflexión articula varios puntos en un escenario social del colonialismo-estamentalismo-racismo-generización que en Guatemala se muestra de una manera más extrema y visceral, por la conformación histórica que ha normado las relaciones sociales desiguales con el lenguaje explícito de la violencia y la confrontación. Las mismas mujeres entrevistadas se referían a ello: 
La sociedad colonial se refuncionaliza a través de formas super racistas, yo creo que están criados así. Los condominios fueron concebidos de esta manera porque toda la publicidad: "es un lugar exclusivo". Todo fue planificado, la gente se siente distinta. Además los muros están hechos para "no son igual a mi", "que no entren". Son exactamente para separar (Pili).

Esto implica que las dimensiones ideológicas conservadoras del mensaje asociado a la vida de condominio entienden la sociedad desde la jerarquía y la diferencia, y no a partir de la utopía de la igualdad ciudadana, además la interpretan desde las relaciones personales e individualidades obviando las causas y procesos históricos de desigualdad y violencia. A los condóminos les motiva una pretensión estamental donde esperarían el reconocimiento efectivo de unos privilegios por tratarse de disciplinados ciudadanos consumidores.

En los diferentes condominios se ubican y confluyen clases medias altas híbridas e inclasificables: desde arribistas o emergentes-globalizados, clases medias tradicionales, descendientes de la oligarquía, clases medias de sube y baja, profesionales liberales y académicos, rentistas, foráneos globales, funcionarios públicos, políticos, empresarios legales o narcotraficantes y otras clases criminales. Un popurrí de formas, relaciones, conceptos sociales y capitales culturales que trascienden el análisis de clases. Sin embargo, en otros espacios se encuentra que la actual heterogeneidad social opera en una "integración hacia arriba", donde las disputas parecen conciliarse. En Guatemala esta competencia por el estatus y por las categorías de definición de los códigos morales podría ser más cruda y encarnizada. ${ }^{26}$

Resulta conocido cómo en Guatemala hay un cuidado más férreo de la seguridad que en otros lugares produciéndose altos grados de pistolización, securización, sicariato, carros blindados, chaquetas antibalas, cámaras, guarurismo, servicios de seguridad privada, que están a la orden del día, más ante el actual pavor hacia extorsiones, secuestros, limpiezas sociales, que afectan a toda la sociedad. Al mismo tiempo, los sectores de la sociedad guatemalteca serían cómplices de estas respuestas ante las violencias contemporáneas al aceptar dosis de militarización aceptable en la convivencia autoimpuesta con todos estos componentes intimidantes (Rosina Cazali, comunicación personal).

Mientras, la oligarquía procede y justifica esta defensa armada que provoca la radicalidad social y se manifiesta en unos extensos desprecios sociales por la vida para proteger intereses, estatus, patrimonio, nivel social (Krznaric, 2007; Bull, 2014). Quizá las dificultades en la sostenibilidad relativa del estatus y el consumo en estos sectores emergentes permiten comprender el nivel de ira y agresividad que concentran. Estos desprecios se trasladan al interior del hogar. De nuevo esta tesis habría que revisarla, pero la impresión es que en estos condominios de privilegio la cultura de servidumbre se aleja de la ideología del afecto patriarcal y paternal que supondría. Con el enunciado "ser como de la familia" los patrones buscan obtener una identificación básica y la superioridad que estos representan. La mano de obra o el cuerpo de la servidumbre no solo se compra y controla, sino que también se trata de incidir en su identidad. Esta delicada 
dimensión involucra el lado afectivo de las relaciones de servidumbre en el espacio doméstico. Ray y Qayum (2009), quienes estudiaron el caso de Calcuta, observaron "una estructura de sentimientos" en la que encajaban patrones y servidumbre y era vivida y practicada por ambos lados desde "la retórica del amor" como una estrategia ideológica en la que se representaba una ficción interesada que permitía que las desigualdades estructurales y la dominación fueran inadvertidas o reinterpretadas en términos de acuerdos mutuos, afectos, obligaciones y lealtades. Sin embargo, en Guatemala el nivel de desconfianza es muy fuerte y la dimensión afectiva del trabajo doméstico se ha perdido. En otros espacios se espera un servir con gusto, educación y "afecto" (Camus y de la $\mathrm{O}, 2014$ ), aquí se espera directamente su invisibilidad en un menosprecio extremo.

En este "traslado al interior" de los hogares no puede dejarse de lado un mundo oscuro que será preciso investigar con más detenimiento: los altos niveles de violencia contra las mujeres y de feminicidios en Guatemala que no solo se producen en sectores populares. La renovación de los arquetipos de género en estos ambientes -a pesar de otras transformaciones que también se dan- con la exaltación del macho prepotente, y la cosificación y sexualización subordinada de las mujeres permite que el ejercicio del poder pueda producirse en forma de violencias psicológicas y otras que se encarnan o materializan en los cuerpos de ellas.

A lo largo del texto se muestra la omnipresencia del consumismo. El mercado es clave porque en él radica la hegemonía del orden (neo)liberal y en este escenario la sociedad se reorganiza desde esta lógica donde los ciudadanos consumidores se distinguen por el acceso al mismo y se produce "la invención de los pobres" como los nuevos sujetos de políticas sociales del Estado a través de las transferencias condicionadas (Pérez Sáinz, 2014). Esta dinámica de desigualdad entiende a estos como consumidores defectuosos y, se podría decir, poco esforzados, lo que permite a los buenos ciudadanos deslindarse de responsabilidades sociales. A mi entender este comportamiento se refleja espacialmente en el residir en fraccionamientos cerrados escoltado por el crecimiento de las vías de comunicación y de los conspicuos centros comerciales y servicios como gimnasios o colegios de élite o de los megatemplos evangélicos.

Estos últimos y el mensaje de motivación del exceso y del éxito que pregonan se pueden entender como refuerzos culturales del proceder de las clases "ganadoras" -o de aquellos que quisieran serlo- y serían otra especificidad significativa en Guatemala. Aquí hay una creciente feligresía evangélica entre las clases medias pujantes incorporadas a las nuevas creencias y modalidades religiosas de los megatemplos -especialmente en su versión evangélica neopentescostal- donde se representan sin modestias (Bjune, 2012 y Bull, 2014).

Los megatemplos "son un termómetro del tamaño y prosperidad de las clases medias de cada país: Guatemala a la cabeza" (Rocha, 2012). El discurso y la materialización de estos megaproyectos espirituales se conectan con los afanes del capitalismo sagrado, los meganegocios-megaespectáculos, el emprendedurismo y el ascenso social estando más cerca de la celebración del consumo que de la sacralidad. Alimentan la ideología de la prosperidad en un llamado a disfrutar la riqueza aquí y ahora, exhibiéndola en el vestir, en 
el gastar, en el consumir, en el triunfar, que serían las nuevas "virtudes teologales" (Rocha, 2012: 11). Funcionan como escuelas gerenciales o de negocios con un alto manejo de la tecnología, de los medios de comunicación: los pastores como Cash Luna o Harold Caballeros son showmen y parte finalmente de iniciativas internacionales (Bjune, 2012).

La Casa de Dios ya tiene 6 sedes. Su último templo, inaugurado en el 2013, Ciudad de Dios, está en Pinula -en el kilómetro 21 de la carretera a El Salvador- ocupa 38 mil metros cuadrados y tiene capacidad para más de 12000 personas, es el segundo más grande del país después de la Megafráter de la Fraternidad Cristiana de Guatemala en Ciudad San Cristóbal. Su concepción es en grande, no sólo se trata de un templo, también integra otras actividades como deportivas, de ocio, tienen radio propia, escuelas, librería, consulta médica, talleres de manejo de negocios... La demostración de su poder fue contundente en su inauguración al concentrar todas las personalidades del mundo político -incluido el Presidente-, mediático, diplomático, de estrellas populares. ${ }^{27}$

Los dinerales que cuestan estas construcciones se alimentan de los diezmos:

La María y la Paty son evangélicas de la Casa de Dios; pasan tarjetas de crédito para el diezmo, y todas sus hermanas y toda su familia son de esas iglesias y dan el diezmo, los católicas somos más tacaños, si podemos damos un quetzal o 5 quetzales o las fichitas.

Las páginas webs indican cómo efectuar este pago con todo tipo de tarjetas electrónicas, su objetivo de marketing mercantil acumulativo se manifiesta sin pudor, son "donativos on line" (Rocha, 2012: 6).

Como señala Bull (2014), el evangelio de la prosperidad de los megatemplos es un recurso más de las élites, parte de toda una práctica política que facilita la creación de redes y oportunidades que les ofrecen ventajas importantes. Los evangélicos que aparecen referidos en las pocas entrevistas realizadas corresponden al prototipo: gerentes muy activos, en que la pareja y toda la familia está inmersa en las actividades de estos foros que entienden como un espacio de relaciones (para los negocios y para los hijos al futuro). Jenny y su marido -aparentemente domesticado- cumplen con el prototipo de mujer de condominio ("la verdad es que nos complementamos"). Dejó de trabajar en la crianza de los hijos, ahora lo retomó con entusiasmo porque "te proyectas, es algo motivador para el crecimiento personal". Es una mujer activa, agendada y multifuncional:

Tengo que andar con el celular, tengo la ipad también, es que es más portátil, puedo llevar presentaciones, y puedo llevar toda la agenda, y puedo llevar notas. Y sin el celular no vivo. Un iphone que me lleva todo. Tengo correo, ahí tengo todo, ahí puedo contestarte lo que tú quieras en un minuto.

Va al gimnasio una hora por las mañanas, hace yoga y pesas, trabaja de diseñadora, colabora en proyectos de turismo con su esposo, tiene a los hijos en clases diversas en las tardes: gimnasias, box, inglés. Los fines de semana hace shopping, acude a una sesión de belleza cada 15 días y el domingo a la iglesia en San José Pinula. 
Yo soy cristiana, ya nacimos. Es Casa de Dios. Mis hijos y yo nos identificamos... y la sociedad de jóvenes es más grande, creo que es muy conveniente que se relacionen y ampliarles un poco el núcleo social, allá conocen más gente, e igual yo me siento a gusto, conozco a mucha gente de ahí.

El caso de Jenny permite hipotetizar que la neocolonialidad evangélica también está generizada y de forma más declarada con el modelo de los matrimonios de compañía -hombre y mujer proveedores y educadores responsables de su prole- que serían demostrativos hacia el resto social en estas élites emergentes, aunque no sean estrictos en su cumplimiento como vimos en testimonios previos. Las mujeres entrarían a cobrar un papel especial a como se les ha considerado quizás porque la plataforma de éxito no funcionaría sin su aporte complementario.

Continuando con lo anterior, los discursos de los pastores-empresarios se centran en familia, status quo, trabajo, disciplina, vida ordenada, abstención de vicios, aunque reitero, como hemos visto, no necesariamente se cumplen estos preceptos. Los problemas sociales los refieren en términos morales de crisis de valores nunca relacionados con causas ni soluciones estructurales ni políticas (Bjune, 2012). Su culto sin reservas a la acumulación justifica la desigualdad económica, la justicia social no es parte de sus preocupaciones.

Buena parte del desarrollo de los temas de los pastores son ellos mismos y sus peripecias en sus procesos de éxito, "cultivan un narcisismo militante" (Rocha, 2012: 5). Este autor interpreta que el credo neopentescostal y su "irresponsable optimismo mágico... hacen creer en la posibilidad de un éxito siempre inminente en un mundo de estructuras económicas tambaleantes" (ibid.: 12).

En la teatralización celebratoria de la neocolonialidad, el abrazo al criollismo y al espíritu neoconquistador del fomentado 'emprendedor' no puede quedar mejor reflejado en términos estéticos contemporáneos que en el símil entre La Antigua Guatemala y la novísima Ciudad Cayalá. Ambos espacios se pueden entender como complementarios en forma y contenido. La primera legitima e impone el estilo colonial más clásico con sus detalles arquitectónicos como bóvedas, cúpulas, pérgolas, rejas de hierro fundido. El segundo es todo un reclamo de los ancestros coloniales desde este siglo permitiéndose un guiño a otros modelos civilizatorios en su posmodernidad y neourbanismo (una ciudad joven a la vintage). En este proyecto mixto de mini ciudad que combina negocios y residencia y trabajo, Jenny nos desnuda que

Cayalá está nítido y está abierto y está funcionando. Ya hay gente viviendo. Mmm... la verdad es que las construcciones son muy malas. Todo lo que tú ves dices, 'ay qué lindo', pero cuando vas y tocas, mala construcción, carísimo. Si te das cuenta tiene muchas características de Antigua, porque todavía caminás en Antigua y lo hacés en Cayalá, porque es una ciudad con un poco más de seguridad. Es una ciudad nueva y tiene características coloniales....

Ciudad Cayalá ha sido publicitada como una "ciudad privada" para los ricos. Se imagina como ciudad porque supera la función residencia y se acompaña de un proyecto 
urbanístico: parques, comercios, discotecas, departamentos, parqueos, oficinas, restaurantes. Por ahora se han construido 14 hc., pero espera ampliarse a más de 300 hc. No se trata de una ciudad "cerrada" o amurallada, su seguridad se ha diseñado a través de sofisticadas cámaras y de un sinnúmero de guardias situados estratégicamente y comunicados entre sí. Su éxito se ha debido en buena parte por esta espectacularización simulada, como una disneylización de Antigua sin antigüeños del pueblo por esa efectiva secesión social: es difícil ver población pobre ni oscura que no esté debidamente higienizada a través de sus uniformes, son una servidumbre como guardias o recamareras. Se logra un espacio público restringido a iguales -criollos- en el que quisieran moverse siempre. Algo que llama la atención de Cayalá y que la diferencia de Antigua, además del monumentalismo sin concesiones a las curvas y al barroquismo antigüeño, es el color. Es de un blanco impecable y ello remite a aquel testimonio de remembranza de un miembro de la oligarquía guatemalteca: "Me gusta profundamente España y cada vez me identifico más con ella porque todo es blanco, sus pueblos son blancos, su gente blanca, huelen a blanco y no a carbón y leña como nuestros pueblos de indios" (Casaús, 1990: 213).

El resultado de vivir entre esferas encapsuladas es que las nuevas generaciones no conocen otros mundos socioespaciales posibles: “¿cuántos adolescentes hay que no conocen la zona 1?" (Pili). O

los hijos de la Chabeli, los hijos de la Leslie, de la Anabel, de la Paty, de la Angelina, ellos no conocen este mundo, su medio es allá arriba todo lo que es la carretera El Salvador, la zona 16, quizás nomás para La Antigua (Irene).

Al preguntarle a la oligarca Olga Alvarado de González si está de acuerdo con que el condominio es una separación de la mayoría social, contesta: "Eso es absolutamente cierto... hay hermosas áreas en las que la verdad es que uno vive en una 'cápsula de crista... se puede vivir toda tu vida ajeno a la realidad del país" (Krznaric, 2007: 123). Y explicita que las consecuencias de esta separación pueden ser peligrosas porque estos sectores en aislamiento causan resquemor por su nivel de vida y porque no van a saber nada ni a preocuparse por la realidad del país "porque simplemente no ves, estás ciego"' (ibid.: 123).

Esta mujer, refiriéndose a los jóvenes oligarcas, piensa que viven el mismo estilo de vida "expatriado" que sus padres. Pero matiza que se encuentran más encapsulados, ya que están educados en universidades -muchas extranjeras-, se mueven en oficinas de finanzas y comercio de la metrópolis y no llegan a las fincas con lo que se limita su contacto con otras personas trabajadoras más pobres. El autor entiende que aunque estas generaciones podrían tener unas miras más amplias por el bien común “...quizás ellos escogieron no ver” (Krznaric, 2007: 124).

Todos estos ejemplos tienen implicaciones en esos procesos de desocialización que en la academia etiquetamos como fracturas, desigualdades, exclusiones, ciudadanías contrapuestas y que muestran cómo se están produciendo cargas de violencia contenida o de "resentimiento social" (Pérez Sáinz, 2014). Es necesario preguntarse 
cómo se están dando estas tensiones intra y trans clase, cuáles son las prácticas sociales, políticas y culturales hacia el resto social en estos grupos y las visiones del mundo que manifiestan. Preguntarse qué efectos supone una mayor presencia pública y política de las élites y de sus mujeres combinada con un creciente aislamiento social y con una interpretación de la sociedad por relación personal o por valores morales y no por causas y procesos históricos de desigualdad y violencia.

Finalmente reiterar la necesidad investigar a los sectores de élite y otros emergentes que son los promotores y beneficiados de estos escenarios privilegiados que se promocionan como el imaginario de vida deseable para todos. Son "clases vitrina" que hegemonizan discursos y representaciones como guías civilizatorias hacia el resto social, por eso es importante analizarlos y cuestionarlos.

\section{Notas}

1 Sus nombres están cambiados y he tratado de limitar cualquier posible identificación de sus personas porque todos sabemos que su reconocimiento no es difícil entre estos sectores.

Este mapa de Ciudad de Guatemala y la mancha urbana muestra la discordancia entre ambas. La municipalidad de Guatemala está administrativamente organizada por zonas pero algunas aún no son parte de la mancha urbana. Esta mancha se extiende por municipios vecinos, algunos ya conurbados, de hecho se habla de Área Metropolitana de Guatemala pero no se logra definir ni institucionalizar cuáles serían los municipios incorporados a esa lógica común. En el caso que nos interesa se produce la expansión "urbana" sobre Santa Catarina Pinula y San José Pinula. Para Santa Catarina, el sistema de Google entiende su área como urbana a pesar de que buena parte no ha sido construida y su densidad poblacional es muy baja, previendo su privatización y cambio de uso de suelo en un mediano plazo. Mientras que San José también se incorpora a estas lógicas pero no se considera parte de esta mancha urbana como el municipio anterior, en el mismo las funciones agrícolas son muy fuertes entre la creciente ocupación -como islas- de residenciales, colegios de élite, campos de golf y country clubs e incluso de la presencia de la Granja Penal de Pavón.

3 La descripción y crítica a esta secesión social se repiten en el mundo (para América ver por ejemplo: Davis sobre Los Ángeles 1992, Caldeira en Sao Paulo 2007, Cabrales para América Latina 2002, Svampa en Buenos Aires 2008, Camus en Guadalajara 2015).

La Cañada es un clásico residencial de grandes mansiones del cuerpo diplomático y la oligarquía en la zona 14 que remite a los años 50. Krznaric observa a partir de La Cañada cómo "desde el aire, es posible ver las grandes extensiones de zonas verdes privadas monopolizados por los ricos" (2007: 121). Este mismo autor nos recuerda que, como los campesinos o los mayas, la oligarquía también desarrolla un corpus cultural o cosmovisión sobre sus fincas "ancestrales" por los profundos afectos ligados a vínculos familiares históricos (Ibíd: 121), algo que se puede pensar en el ámbito urbano.

Pierre Bourdieu protagoniza la discusión sobre la distinción que identifica y clasifica la diversidad de gustos, siendo el gusto esa "disposición adquirida para 'diferenciar' y 'apreciar"”. Así la distinción establece el lugar del sujeto en el orden social enclasándolo y afirmando la diferencia inevitable (Bourdieu, 2000: 477). 
El estatus "se refiere al valor e importancia que uno tiene ante los ojos del mundo" (De Botton, 2004: 7), las consecuencias de un estatus elevado suponen recursos, libertad, espacio, comodidad y la sensación de que le tienen en consideración.

$7 \quad$ La expansión de emprendimientos residenciales privilegia el crecimiento horizontal frente a la redensificación vertical de la metrópolis provocando el alejamiento de los lugares de trabajo y problemas de tráfico. La falta de planificación pone a prueba los límites de esta forma suburbana de vida por la saturación de las vías, algo que se está haciendo notar con fuerza en Ciudad de Guatemala.

Por su organización los condominios funcionan como una economía de clubs territoriales (territorial club economics) en el sentido que son colectivos que desde su exclusividad se establecen como fraccionamientos privados sobre acuerdos como propietarios-miembros con autogobierno para compartir el consumo de bienes específicos al interior de unas fronteras territoriales (Glasze 2005: 224).

Miami se puede considerar la capital cultural de la élite latinoamericana. En Guatemala los vuelos a Los Ángeles son mucho más caros y la consideran una ciudad "naca" donde "hay mucho chicano", mientras para "Miami te dan ofertas de hasta 250 dólares".

Este artículo apareció en El Periódico el 18 julio del 2004.

Para Bull, la élite son "grupos de personas que, debido a su control sobre los recursos naturales, económicos, políticos, sociales, organizativos, simbólicos (experiencia/conocimiento) o coercitivos, están en una posición privilegiada para influir de manera formal o informal en decisiones y prácticas que tienen un amplio impacto en la sociedad" (2014: 120); expone que las élites en Guatemala basan su fuerza en el control de redes que manejan: dinero, medios de coacción, información e ideas e ideología, con ello explica cómo su poder y su competencia se contrapone a la debilidad de las instituciones formales minando el funcionamiento de la democracia en el país. Yo entiendo las élites en su dimensión cultural, no tanto como élite económica, tecnócrata o política. Me interesan las élites por ver cómo están enraizadas en su contexto y cuáles son las estrategias culturales que las permiten mantener el estatus, cómo se reproducen, cómo se representan, cómo sientan su comunidad moral y política orientadora y establecen sus estilos de vida como los hegemónicos (Shore, 2002).

13 Ya no se puede hablar de una élite coherente, sino de segmentos diferentes que a veces colaboran entre ellos como entran en disputas. Es una diversificación resultado de la emergencia de nuevas actividades económicas incluso ilegales y criminales como el narcotráfico (Martí i Puig y Sánchez-Ancochea, 2013: 19).

14 Maristella Svampa se refiere a una restringida ciudadanía patrimonialista, basada en la autotutela individual y en la autoregulación de parte de ciertos sectores propietarios y de alto nivel adquisitivo segregados de la férula de otras normativas públicas y privadas. Es otra forma de relación individuosociedad mediada por un colectivo que se constituye con un régimen de privilegio en sí mismo y no como una ciudadanía igualitaria y universalista. Sugiere que la ciudadanía patrimonialista puede derivar en "impunidad de clase" (2008: 281).

15 La ansiedad por el estatus se refiere a un drama interior de "no responder a los ideales de éxito establecidos por nuestra sociedad y que quizás por ello nos veamos despojados de dignidad y de respeto... La ansiedad la provocan, entre otras cosas, la recesión, el despido, los ascensos, la jubilación, las conversaciones con compañeros del mismo sector, las reseñas periodísticas sobre personas destacadas y el éxito de los amigos..." (De Botton 2004: 8). 

Santa Catarina Pinula.

17 La teoría de la colonialidad formulada por Aníbal Quijano (2000) presenta una estructuración de las sociedades y los Estados-nación en América Latina sobre la idea de raza que asocia los roles y lugares de cada grupo en la división social del trabajo. Yo entiendo que la colonialidad no solo se expresa en el campo de la dominación político-económica de unos pueblos sobre otros sino también en la concepción y práctica de las relaciones sociales que combinan lo colonial y lo estamental (Camus y de la O, 2014).

18 Marcela Lagarde desarrolla este concepto de madre-esposa en el sentido de que las mujeres viven en el ser para y de otros; donde maternidad y conyugalidad son esferas vitales que "organizan y conforman los modos de vida femeninos, independientemente de la edad, de la clase social, de la definición nacional, religiosa o política de las mujeres" (1990: 349).

19 Freud identificaba al narcisismo de la mínima diferencia en su libro El malestar de la cultura en los años 30 del siglo pasado, como la obsesión por diferenciarse de aquello que resulta más familiar y parecido. Podríamos pensar que este comportamiento se ha vuelto generalizado en este mundo de una cultura de la superficialidad (Sennet 2006).

20 Como lo anterior esto se liga a que la subjetividad moderna se centra en vender la autoimagen, crear narrativas propias y efímeras en Facebook, Youtube o con los selfies que se generan en la clave del mercado libre y de la rentabilidad que domina las políticas globales (Sennet, 2006; Bauman, 2007).

21 Y que las hace también motivo de violencia psicológica y física como es el caso ya paradigmático de la desaparición supuestamente por su marido de Cristina Siekavizza en un residencial: "estoy segura que es pura violencia, fue pura violencia de pareja, como ella deben haber cientos de mujeres golpeadas adentro, cientos... la gente no quiere ver porque cómo les cuesta el tema de la violencia... o siguen creyendo que es un tema muy privado y que en eso no te metes" (Pili).

Esta autora dice que a medida que avanza el mercado "la familia deja de ser una unidad de producción para transformarse en una unidad de consumo" (Russell, 2008: 62).

La bibliografía sobre racismo es muy abundante y de calidad en la región centroamericana, por eso no me voy a detener en ella, dentro de la que está incluida consultar Casaus (1990) y Pérez Sáinz (2014).

Me refiero a la servidumbre doméstica y no al trabajador doméstico para destacar la faceta servil y no contractual del empleo doméstico.

Cuando se instala en Madrid Odette Arzú en una casa de tres pisos con 6 hijos, loro y perra, tiene un ejército de servicio: nanas, cocinera, chofer... y reconoce que cuando se desaparecían cosas en la casa: pañuelos, calzoncillos, bolígrafos, brasieres le "echábamos la culpa al numeroso servicio" (2005: 133) para descubrir al final que habían sido los hijos pequeños.

En Buenos Aires se encuentra una incipiente red socioespacial de sectores medios en ascenso y clases altas y medias altas consolidadas que buscan mantener el equilibrio en la emergencia de un espacio común de sociabilidad donde los diferentes círculos se homogenizan en un proceso de integración "hacia arriba" (Svampa, 2008).

27 Entre las iglesias neopentecostales en la capital construidas entre 2003 y 2007 destacan La Familia de Dios para un aforo de 10000 personas; El Shaddai para 5 000, Lluvias de Gracia para 6500 y La Megafráter con 12200 lugares. 


\section{Bibliografía}

Aguilar, Adrián Guillermo y Pablo Mateos. “Diferenciación sociodemográfica del espacio urbano de la Ciudad de México". EURE, 37, 110, (2011): 5-30.

Arzú Castillo, Odette. Añoranzas y saudades.Guatemala: F\&G editores, 2005.

Bauman, Zygmunt. La sociedad sitiada. México: Fondo de Cultura Económica, 2007.

Bjune, Maren Christensen. “Te Deum Cristiano Evangélico: 'The Evangelical' in Guatemalan Politics". Iberoamericana. Nordic Journal of Latin American and Caribbean Studies XLII, 1-2 (2012): 109-133.

Bourdieu, Pierre. La distinción. Criterio y bases sociales del gusto. México: Taurus, 2003.

Bull, Benedicte. "Towards a Political Economy of Weak Institutions and Strong Elites in Central America". European Review of Latin American and Caribbean Studies, 97, (2014): 117-128.

Cabrales Barajas, Luis Felipe (coord.). Latinoamérica: países abiertos, ciudades cerradas. México: Universidad de Guadalajara-UNESCO, 2002.

Caldeira, Teresa Pires do Rio. Ciudad de muros. Barcelona: Gedisa editorial, 2007.

Camus, Manuela. "Mujeres cotificadas. Una etnografía en los cotos catrines de Guadalajara". Revista La Ventana, 34, IV(2011): 191-234.

"Mujeres de coto en Guadalajara, Jalisco: dimensión neocolonial y simplificación social". Revista Amerika, (2013). <http://amerika.revues.org/4276>.

- Vivir en el coto: fraccionamientos cerrados, mujeres y colonialidad. México: Universidad de Guadalajara, en prensa.

Camus, Manuela y María Eugenia de la O. "El discreto encanto de la colonialidad tapatía. Notas sobre la cultura de servidumbre". Trabajadoras en la sombra. Dimensiones del servicio doméstico latinoamericano. Ed. Durin, de la O y Bastos. México: Centro de Investigaciones y Estudios Superiores en Antropología Social, 2014. 145-171.

Casaús, Marta. Guatemala: linaje y racismo. Costa Rica: FLACSO-Costa Rica, 1990.

Connell, Raewyn. "Global Tides: Market and Gender Dinamics on a World Scale". Social Currents,1, I(2014): 5-12.

Connell, Raewyn W. y James W. Messerschmidt. "Hegemonic Masculinity: Rethinking the Concept". Gender and Society, 19 (2005). <http://gas.sagepub.com/content/19/6/829>

Davis, Mike. City of Quartz. Nueva York: Vintage Books, 1992.

De Botton, Alain. Ansiedad por el estatus. Colombia: Taurus, 2004.

Douglas, Mary. Pureza y peligro. Un análisis de los conceptos de contaminación y tabú. España: Siglo XXI, 1973.

Gellert, Gisella y Julio César Pinto Soria. Ciudad de Guatemala: dos estudios sobre su evolución urbana (1524-1950). Guatemala: Centro de Estudios Urbanos y Regionales, Universidad de San Carlos de Guatemala, 1990.

Glasze, Georg. "Some Reflections on the Economic and Political Organisation of Private Neighbourhoods". Housing Studies, 20, 2(2005): 221-233.

Honneth, Axel. "Visibilité et invisibilité. Sur l'e epistemologie de la 'reconnaissance'". Revue du Mauss, 23, (2004): 137-151. <http://www.cairn.info/revue-du-mauss-2004-1-page-137.htm>.

Illouz, Eva. El consumo de la utopía romántica. El amor y las contradicciones culturales del capitalismo. Buenos Aires: Katz, 2009.

Krznaric, Roman. What the rich don't tell the poor. Conversations in Guatemala. Documento, 2007. Le Breton, David. Antropología del cuerpo y modernidad. Buenos Aires: Editorial Nueva Visión, 2002.

Lagarde, Marcela. Cautiverios de las Mujeres: Madresposas, Monjas, Putas, Presas y Locas. México: Universidad Nacional Autónoma de México, 1990. 
Lugones, María. “Colonialidad y género”. Tábula Rasa,9 (2008): 73-101.

Martí i Puig, Salvador y Diego Sánchez-Ancochea. "Introduction. Central America's triple transition and the persistent power of the elite". Handbook of Central American Governance. Eds. Diego Sánchez-Ancochea y Salvador Martí i Puig. Routledge International Handbooks, 2013. 4-22.

Palencia, Mayra. "Elites y lógicas de acumulación en la modernización económica guatemalteca". CLAS Working Paper. Web. 19 april 2013. <https://www.american.edu/clals/ upload/Palencia_Elites_Ejes_Acumulaci\%C3\%B3n_Guate.pdf $>$

Pérez Sáinz, Juan Pablo. Mercados y bárbaros. La persistencia de las desigualdades de excedente en América Latina. San José, Costa Rica: FLACSO, 2014.

Quijano, Aníbal. "La colonialidad del poder, eurocentrismo y América Latina". La colonialidad del saber: eurocentrismo y ciencias sociales. Comp. Edgardo Lander. Buenos Aires: Perspectivas Latinoamericanas-CLACSO- UNESCO, 2000: 201-246.

Raka, Ray y Seemin Qayum. Cultures of Servitude. Modernity, Domesticity, and Class in India. Stanford: Stanford University Press, 2009.

Rocha, José Luis. "Los jinetes del desarrollo en tiempos neoliberales: las megaiglesias del capitalismo sagrado". Revista Envio, 387, (2012). <http://www.envio.org.ni/articulo/4602>.

Russell Hochschild, Arlie. La mercantilización de la vida intima. Apuntes de la casa y el trabajo. Argentina-España: Editorial Katz, 2008.

Sennet, Richard. La cultura del nuevo capitalismo. Barcelona: Anagrama, 2006.

Svampa, Maristella. Los que ganaron. La vida en los countries y barrios cerrados. Argentina: Editorial Biblos, 2008.

Torres Rivas, Edelberto. “Guatemala 2000: un edificio de cinco pisos (una introducción a un análisis de estratificación social)". CLACSO, 2008. <http:// bibliotecavirtual.clacso.org. ar/ar/libros/secret/cuadernos/torresri/torresri.pdf $>$.

Valdez, José Fernando. El gobierno de las élites globales: cómo se organiza el consentimiento. La experiencia del Triángulo Norte. Guatemala: Universidad Rafael Landívar, 2015.

Veblen, Thorstein. Teoría de la clase ociosa. México: Fondo de Cultura Económica, Colección Popular n. ${ }^{\circ}$ 50, 2005.

Weber, Max. Economía y sociedad. México: Fondo de Cultura Económica, 1967.

Manuela Camus. Española, es doctora en antropología social por el Centro de Investigaciones y Estudios Sociales en Antropología Social de Guadalajara, México. Actualmente es profesora investigadora en el Centro de Estudios de Género de la Universidad de Guadalajara, en México.

Ha publicado en el 2015 junto con Santiago Bastos y Julián López Dinosaurio reloaded. Violencias actuales en Guatemala, y en solitario Vivir en el coto. Fraccionamientos cerrados, mujeres y colonialidad. Su último libro fue La sorpresita del Norte. Comunidad y migración internacional en Huehuetenango (2008). Y sus últimos artículos "Fronteras, comunidad y violencias", Desacatos, N. ${ }^{\circ}$ 38, 2012; "Mujeres de coto en Guadalajara, Jalisco: distinción neocolonial y simplificación social", Revista Amerika. Mémoires, identités, territoires (http://amerika.revues.org/4276), y "La acción política de las viudas de pilotos en la ciudad de Guatemala", European Review of Latin American and Caribbean Studies, N. ${ }^{\circ} 97$ (2014) October.

Contacto: manuelacamus@gmail.com 